phthisis. In a former part of this paper it was stated that during the previous trenty years, as compared with the last ten years, at Gibraltar, inflammatory affections were more prevalent, and at Malts they were one-third more in number, and yet, at both stations, the amount of consumption was almost identical throughout the two periods. That the fact of this total want of relation may be clearly seen, I have constructed Tables XVI and XVIr.

Thus, in Bermuda, where there were only 23 cases of pneumonia, there were 100 cases of phthisis, and in Nova Scotia where there were nearly fifteen times as many cases of pneumonia, there were only 150 cases of phthisis. In Canada, with 1,589 cases of pneumonia, there were only 524 cases of phthisis, whereas, in the foot guards at home, with only 497 cases of pneumonia, there were 654 of phthisis. Again, in the naval force, 2,598 cases of pneumonia correspond with 437 cases of phthisis, while in the military force, 2,281 cases of pneumonia correspond with 629 of phthisis.

\section{TABLE XVII.}

The number of cases of "acute and chronic catarrl", with the proportion of deaths and recoveries, and the number of admissions into hospital for phthisis, among the troops, in the C'nited Kingdom, the Mediterraneun, and British America, and in the aggregates of the naval and military forces serving in the Mediterranean.

\begin{tabular}{|c|c|c|c|c|}
\hline & Catarrh. & Died. & Recovered. & P'hthisis \\
\hline Lnited Kingdom: & & & & \\
\hline Dragoon guards \& dragns. & $73: 21$ & +1 & $73 \times 0$ & 386 \\
\hline Foot guards $\ldots \ldots \ldots \ldots$ & $4 \times 9: 2$ & 14 & 4878 & 604 \\
\hline Infantry of the line .... & $2 \cdot 2863$ & 190 & 22673 & $165 \tau$ \\
\hline Gibraltar................ & $35: 2$ & 11 & $35+1$ & 106 \\
\hline Malta ............... & 3402 & $2 \pi$ & 3375 & 129 \\
\hline Malta fencibles & 62 & 3 & 59 & $\tau$ \\
\hline Ionian Isles .. & 2980 & 20 & 2951 & 145 \\
\hline Santa Maura . & 92 & None. & $1+2$ & 5 \\
\hline Bermuda.......... & 1246 & 68 & 1178 & 100 \\
\hline Nova Scotia, N. Brunsw. etc. & 4185 & 46 & $413 !)$ & $1 \pm 9$ \\
\hline 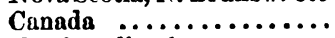 & 11540 & 111 & 11429 & 524 \\
\hline Newfoundland & $0 \check{1}$ & 2 & 649 & 15 \\
\hline Naval force inMediterranean & $219 \pi 1$ & $2 \tau$ & 21944 & 437 \\
\hline Military force in ditto... & 11314 & 83 & 11231 & $6: 9$ \\
\hline
\end{tabular}

For "catarrh" we may no doubt read "bronchitis", in its various degrees; and thus, the principle that I have elsewhere laid down, that bronchitis can in no sense be regarded as a cause of tuberculosis, and that bronchitis alone can in no sense be regarded as a cause of consumption, is confirmed by these statistics. The sailor, who is half his time on deck. in periods of four hours duration, every night and day, constantly leaving his bed at twelve at night, or four in the morning, and passing from an over heated atmosphere to the open air, with exposure to all the vicissitudes of the weather, is twice as frequently attacked with catarrh or bronchitis as the soldier, who is only on guard every fourth or fifth night, and remains exposed but for two hours at a time, during which he is generally protected by his sentry box or great coat; and with this increased liability to bronchitis on the part of the sailor, and the actual occurrence of double the amount of the catarrhal affections, the sailor is much less liable to consumption than the soldier.

I have thus extracted from the original reports the statistics having a direct reference to tuberculosis, and more especially to pulmonary consumption, and placed the whole of the facts in a connected statement before the readers of the Assocration JoURNaL, believing that they are well calculated to promote the study of some very important points in the history of tuberculous diseases. I shall have occasion to refer to the tables in a future paper: in the meantime, they appear to justify the following conclusions :-

That tuberculosis is more frequent in the army, at home and abroad, than in the ciril population of the United Kingdom.
That it is more frequent in the army serving at hom: than in the army serving either in the Mediterranean or in British Americs.

That it is more frequent in the army serving in the Mediterranean and Bermuda than in Canada, Nova Scotia, New. Brunswick, etc., and Newfoundland.

That it is much more frequent in the army than in the navy, in the home and in the Mediterranean services.

That the season of the year has no considerable influence orer the production of tuberculosis, or its local expression in the lungs, nor orer its fatality, either in the United Kingdom, the Mediterranean, or in British America.

That there is no fixed relation between the amount of inflammatory diseases of the lungs and the amount of tuberculosis, or of consumption. in any of the climates. Where there is the greatest number of cases of inflammatory affections, there is often found the smallest number of cases of consumption; where there is the smallest number of inflammatory attacks, recoveries, or deaths, there is frequently the greatest number of consumptions; and in a third group, the proportionate frequency of intlammatory affections of the lungs and of consumption have a close correspondence.

3, Norfolk Crescent, Hyde Park, Oct. 185i3.

\section{CASE OF FRACTURE OF THE CRANIUM IN AN INFANT AT BIRTH.}

By J. G. SWAYNE, M.D., Lecturer on Midwifery at the Bristol Medical School.

$[$ Read at the Quarterly MLeting of the Bath and Bristol Branch of the Association, S'pt. :20th, 1S53.]

Or Monday, June 6th, Mr. Coster, onc of my pupils, was called to attend Mary MI., aged 29, living in Eugene Street; the messenger desiring him to come as speedily as possible. He arrived at the house in less than a quarter of an hour, when he found the child born, and the funis broken about three inches from the umbilicus. He immediately secured the short end with a ligature, to prevent further hæmorrhage (not much, however, had occurred from the source); and then proceeded to remove the placenta, which was already detached. He was informed by a woman who was present, that the labour came on very unexpectedly, and that the patient was delivered in the upright position, the child falling on the floor. On examining the child's head, he discovered that it was much bruised, and discoloured with blood extravasated beneath the scalp and over the left parictal bone. He applied water-dressing to the injured part, and visited the mother and infant on the two following days. They both seemed to be progressing favourably, and the swclling upon the child's head had become some what reduced in size. For the next three days, the child took the breast fairly, as well as some food, and appeared in other respects well, until Sunday, the 12th (six days after its birth), when the mother perceived that it would no longer suck, and that the countenance was much altered.

Mr. Coster was again sent for about eight o'clock in the evening of the same day, when he found the child struggling in a severe paroxysm of convulsions. The fits recurred every five or ten minutes, and appeared to affect all the muscles of the body. The face was livid, the pulse very quick, and the pupils turned upwards, and apparently contracted. Mr. Coster directed the child to be placed in a warm bath, with cold effusion to the head, and $3 j$ of oleum ricini to be taken immediately. The fits returned very frequently during the early part of the night, and the child seemed to be sinking fast. The pulse was very weak, and almost imperceptible. The bowels had been moved by the oil. The warm bath was repeated, with the addition of a spoonful of mustard ; but the child died at half-past twelve the same night.

A post mortem examination was made on Tuesday by $\mathrm{my}$ request, in which I was assisted by my friend Mr. Coe, and my pupils Messrs. Coster and Granville. The child had the appearance of a healthy male infant, born at the full tims. 
Orer the superior part of the left parietal bone, the scalp was swollen and discoloured to the extert of a half-crown piece; it had very much the appearance of one of those ganguineous tumours or cephalhæmata which are occasionally formed upon the presenting part of the head, in consequence of pressure. On pressing upon it with the finger, clot could be felt beneath the scalp, and, in the centre of this, an irregularity in the bone, which might have been caused either by a bony ridge or a fracture. The head was then opened, and the parietal bone, which was fractured, removed. On examining its inner surface, a clot of blood, rather larger than a shilling, and about a third of an inch thick in the centre, was seen between the dura mater and bone at the seat of the injury. An incision was then made into the external tumour, which laid bare a small clot between the pericranium and bone. On washing away this clot, we discovered beneath it a fissure in the parietal bone, of about an inch and a half in length. Upon that part of the surface of the brain which corresponded to the injury, the vessels of the pia mater were nuch congested. With this exception, there was no other morbid appcarance in the brain, or in any other of the viscera which we subsequently examined. In accordance with my instructions, Mr. Coster stated, in a certificate, that the cruse of death was fracture of, and effusion of blood beneath, the cranium, the result of a fall during birth.

A coroner's inquest was subsequently held upon this case, partly in consequence of our certificate, and partly because the suspicions of the neighbours were excited respecting the cause of death. The woman was unmarried, and had twice before given birth to illegitimate children. I can say very little about this inquest, as, having received no notice of it, neither of us was present; nor could we find any account of it in the Bristol papers. I believe, however, the verdict returned was in accordance with the certificate which we had given of the death.

REMarks. This case presents some features of interest, especially in a medico-legal point of view. The time which clapsed, namely, six days, between the occurrence of the injury and the supervention of convulsions, is worthy of notice. The symptoms produced were not those of compression, properly so called, but rather such as would arise from irritation of the grey matter of the brain; and they do not appear to have been developed until the clot effused underneath the dura mater had acquired a certain degree of hardness. The convulsive attacks were in many respects analogous to those epileptic seizures which we see in the adult, as a result of pressure upon the brain from bony growths, tumours, etc.

Had it been possible to arrive at a correct diagnosis of the nature of the injury during life, the case would, I think, have justified surgical interference. The cranium might have been trephined over the fracture, and the clot removed with some prospect of success, provided the operation had been performed sufficiently early, before the symptoms of cerebral irritation had become fully developed.

In a medico-legal point of view, the case is interesting, as it shows that fracture of the child's cranium may sometimes be a result of delivery in the crect posture.

This is a subject which has been much discussed by medical jurists. Chaussier performed some experiments on the bodies of still-born children, allowing them to fall with their heads downwards on a paved floor, from a height of eighteen inches; and he found that out of fifteen cases, one or other parietal bone was fractured in twelve. On the other hand, the cases collected by Dr. Klein, of Stuttgardt, show that fractures of the cranium as a result of delivery in the upright posture are exceedingly rare. Out of 183 cases, in which the women were rapidly delivered whilst standing, sitting, or kneeling, not one child died nor did any fracture of the bones or severe external injury take place. The explanation of this discrepancy between the results of cases which have actually occurred, and of analogous experiments which have been performed, may, I think, be found in the circumstance that when delivery takes place in a standing posture, the child falls obliquely instead of directly downwards, in consequence of its following the direction of the vaginal canal which is obliquely downwards and forwards, especially near the os externum. It thus becomes expelled forwards against the clothes of the mother, and these, as well as the umbilical cord, serve to break the violence of its fall. Still, howerer, if we can credit the testimony of the woman and those around her, the instance I have just related proves that fracture of the cranium may occasionally result from such accidents. Although the character of these witnesses is by no means above suspicion, yet the circumstantial evidence tends to corroborate their testimony. The cord had all the appearance of having been broken and not cut. According to the account of the woman who was present at the delivery, the child was taken up from the floor, beneath a tablc upon which the mother was leaning at the time of its birth: and we find accordingly that the injury was exactly of that kind and in that situation where we should expect it, when a child falls upon the floor with its head downwards. There appears to have been no ground for supposing that it was intlicted by the mother or any other person present, for the purpose of destroying the child : for, had it been so, it is most improbable that the party inflicting it should not have proceeded to further violence, but have remained satisfied with the result of a blow which caused no appreciable symptoms at the time. Such a view appears to have been taken by the coroner's jury, who, by their verdict, acquitted the parties of any such intention.

Clifton, Bristวl, October 1853.

SINGULAR CASE OF ALOPECIA.

By JOHN I:ARCLAY, M.D., I'hysician to the Leicester Infirmary.

[Read at the Meeting of the Midland Branch of the Association, at Leicester, on Sept. 1st, 185:3.]

Mr. A. B. applied to me in February last on account of complete baldness. He is twenty-four years of age, a printer, of florid complexion, sanguine temperament, steady habits, and married.

He had been working hard in a close and confined room seven months previously, when he noticed the hair begin to fall from the scalp. This was soon denuded, and then his beard and whiskers followed. The hair on the pubes and in the axillax, on the arms and legs, next disappeared, and lastly, the cycorows and cyelashes, so that when I saw him, he was perfectly hairless from head to foot.

Ilis general health was considerably affected; his appetite was good; but the digestion impaired; and he complained of a sensation of languor and general debility. The excreta were normal. I ordered him a preparation of steel, and friction of the scalp, with a stimulating liniment. The form in which I prescribed the latter was two drachms of tinctura lytta to half a pint of rosemary water, which I have usually found a very successful remedy:

In three or four weeks, he found the smarting cease to be produced by this strength of the lotion, and there was no improvement in the state of the skin. I directed him to increase the proportion of the tinctura lytta at his own discretion.

By the end of the second month of treatment, he had gradually come to use pure tinctura lytta for friction to the head, the skin of which was totally insensible to its effects, while the fingers smarted considerably while applying it.

He has continued the intermal remedies with slight intermissions up to the present time, with very marked benefit to his general health, which is now quite reestablished; but there is not the slightest appearance of a return of the hair on any part of the body. When examined with a lens, the bulb of the hair seems gone, but the aperture through which the hair penetrated the cuticle remains. There is a slight down upon the ears, which has never disappeared; but with this exception, he remains perfectly hairless. 